\title{
Porous polypropylene membrane contactors for dehumidification of gases
}

\author{
D. I. Petukhov, Ar. A. Eliseev, A. A. Poyarkov, A. V. Lukashin, An. A. Eliseev \\ Department of Materials Science, Lomonosov Moscow State University, \\ 1-73 Leninskiye gory, Moscow, 119991, Russia \\ di.petukhov@gmail.com, eliseev@inorg.chem.msu.ru
}

PACS 81.05.Rm, 47.56. $+\mathrm{r}$

DOI 10.17586/2220-8054-2017-8-6-798-803

\begin{abstract}
We report the application of porous polypropylene hollow fiber membranes with $100 \times 500 \mathrm{~nm}$ slit pores in membrane contactor for air dehumidification using triethylene glycol (TEG) as an absorbent. Experiment geometry with gas flow through the lumen of fiber and absorbent circulated on the shell side was utilized to enhance water vapor stage cut. The influence of gas flow rate, liquid circulation rate and water content in triethylene glycol solution on the performance of membrane contactor was studied. The obtained results reveal that the limiting step of water vapor absorption for lumen gas flow configuration is the diffusion of water into TEG volume. Using dry TEG solution and high circulation rate the dew point of feed gas can be decreased down to $\sim-30{ }^{\circ} \mathrm{C}$ for the membrane contactor performance of $30-601 /\left(\mathrm{m}^{2} \mathrm{~h}\right)$, while with reducing dew point requirements to $-10{ }^{\circ} \mathrm{C}$ the performance of the contactor over $1 \mathrm{~m}^{3} /\left(\mathrm{m}^{2} \mathrm{~h}\right)$ is achievable.
\end{abstract}

Keywords: dehumidification, membrane contactor, polypropylene membrane, gas-liquid contactor.

Received: 10 October 2017

Revised: 26 October 2017

\section{Introduction}

Gas dehumidification is known as one of the most common technical tasks required in various industrial applications, such as natural gas treatment, air drying, pneumatic fluids conditioning, etc. Dehumidification can be accomplished using cooling cycles [1], including those based on vapor capillary condensation effect $[2,3]$, vapor absorption [4] or adsorption [5] with desiccants and exploiting membrane separation equipment [6]. Among the methods mentioned, gas, dehumidification by vapor absorption with hygroscopic liquids gained most widespread use due to low energy consumption, the absence of water droplets and its high efficiency.

Two types of hygroscopic liquid absorbents are applied commonly for water vapor capture: aqueous solutions of hygroscopic salts (such as, $\mathrm{LiCl}, \mathrm{LiBr}$ or $\mathrm{CaCl}_{2}$ ) which are typically utilized for humidity control in residential or commercial buildings and di- or triethylene glycols (DEG or TEG) used primarily for industrial facilities. The main disadvantages of salt solutions are related to corrosion and salt crystallization [7]. The utilization of salt solutions for apartment air dehumidification is governed by the absence of desiccant pick-up due to the much lower salt vapor pressure in comparison with glycols [8]. Moreover, the comfort humidity values for working and living spaces is ranges from $30 \%$ to $60 \%$. These humidity values can be achieved by using salt solutions and there is no need to utilize strong absorbents like TEG. At the same time, technological applications, such as gas pipeline transport, air compression for pneumatic systems required very low due point values from $-60{ }^{\circ} \mathrm{C}$ to $-40{ }^{\circ} \mathrm{C}$, which can be achieved only by using $99.99 \%$ TEG as a desiccant [9].

Typically gas dehumidification is realized by direct gas-liquid contact in packed columns or bubble towers [4]. However, the interfacial contact area of those contactors depends strongly on the operation conditions, such as flow rate or operating pressure. Tight control of the operation parameters is required to avoid foaming, channeling, flooding or unloading of the dehumidification columns. Gas-liquid membrane contactors where the liquid and gas phases are separated by a semipermeable membrane (especially hollow fiber membranes) were suggested as an alternative technology for overcoming drawbacks of direct gas-liquid contactors [10-12]. Moreover, utilization of membrane contactors allows to increase interfacial contact area over $2000 \mathrm{~m}^{2} / \mathrm{m}^{3}$ compared to $50-600 \mathrm{~m}^{2} / \mathrm{m}^{3}$ typical for classic contact devices [13].

Membrane contactors are generally divided into two groups: non-porous contactors (usually having an asymmetric structure with selective layer) and porous contactors. Despite providing much better isolation of contacting phases, non-porous contactors generally have much lower permeability for the target components, resulting in proportional growth of capital and operational costs in industrial uses. In the case of porous contactors, the gas-liquid interface is formed at the pore necks. Depending on the membrane's hydrophobicity and the type of absorbent, the diffusion of gas molecules or diffusion of absorbed molecules in the liquid occurs within the pores. In the second case, the resistance of membrane is significantly higher due to lower diffusivity in liquid phase in comparison with the gas phase. This necessitates the use of hydrophobic membrane material for dehumidification issues. 
The first demonstration of air drying by membrane contactors was reported by Isetti and Nannei using $\mathrm{LiCl}$ and $\mathrm{CaCl}_{2}$ saturated solutions as absorbents [14]. Further studies of heat and mass transfer in membrane contactors during dehumidification with aqueous $\mathrm{LiCl}$ have been performed by Zhang et al. [15-17]. In contrast, until now, only a little attention has been paid to membrane contactor dryers with DEG or TEG absorbents $[18,19]$. Moreover, all reports found in the literature consider contactors with absorbent flowing to the lumen side of fibers and gas flowing from the shell side. Despite the fact that using lumen liquid in hollow fiber seems logical from a practical viewpoint, as the feed stream flux generally exceeds that of absorbent many times, this configuration significantly decreases the probability that gas molecules will be drawn into the pores of membrane. This potentially leads to incomplete removal of absorbate and failure to achieve equilibrium vapor pressure. Moreover, the usage of lumen liquid requires the use of powerful pumps to push viscous absorbent through small-diameter fibers.

Thus, in the present study, we report the use membrane contactors with opposite configuration: gas flowing in the lumen side of fibers and absorbent flowing over the shell side. Hydrophobic polypropylene (PP) hollow fiber was used in contactor to avoid filling the pores with a liquid. TEG was applied as an ultimate absorbent allowing the attainment of minimal humidity levels. A schematic representation of the dehumidification process is provided in Fig. 1a. The effects of gas and liquid flow rates as well as TEG water content on the performance of polypropylene hollow-fiber membrane contactor were elucidated.
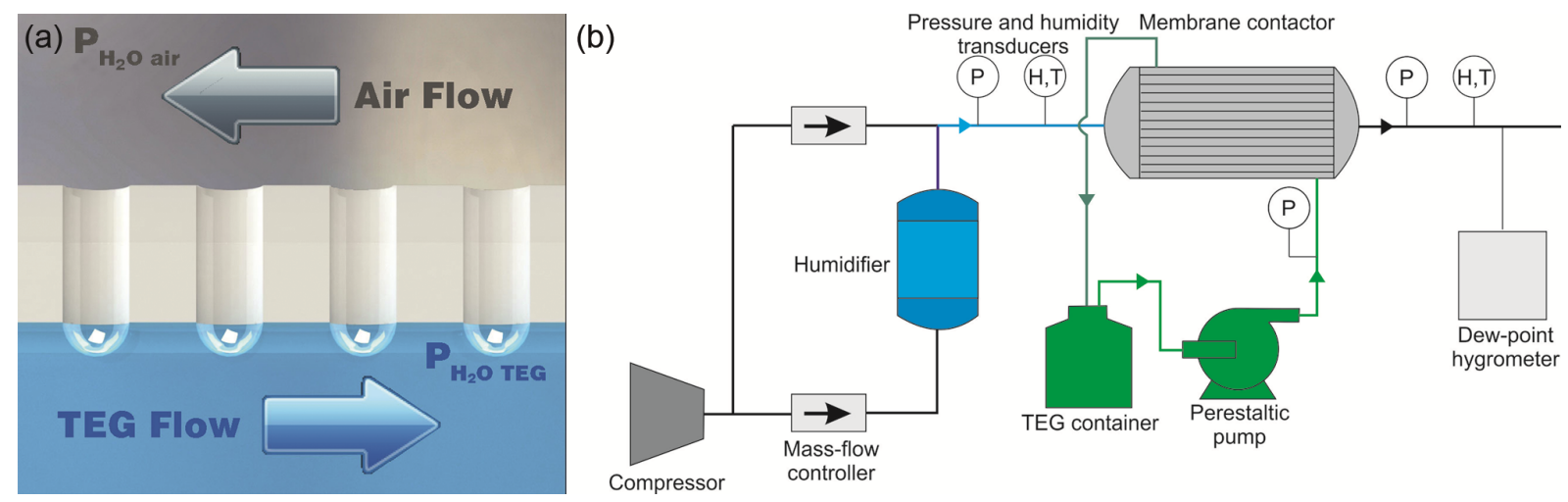

FIG. 1. Scheme of membrane contactor dehumidification process (a) and experimental setup for air dehumidification (b)

\section{Experimental}

Nanoporous polypropylene hollow fiber membranes were supplied by Zena S.R.O. (Czech Republic). A schematic diagram of air dehumidification setup is represented in Fig. 1b. The flux of compressed air was controlled with two mass-flow controllers SLA5850 (Brooks, USA). Air was saturated with water vapor in the humidifier by direct air-water contact. Air temperature and humidity on the inlet and outlet of membrane contactor was monitored by HIH-4000 (Honeywell, USA) sensors. The dew point temperature of treated air was also determined by dew-point hygrometer TOROS-3VY (Ukraine). Lumen side (gas) and shell side (liquid) pressures were controlled by Carel SPKT00E3R pressure transducers and kept at required values to avoid bubble formation in liquid and penetration of liquid droplets into the air stream. A peristaltic pump (BT300-2J, Longer Pump Co, China) was used for TEG circulation. At each run fresh TEG with purity higher than $>99.5 \%$ was used. All dehumidification experiments were carried using feed air with relative humidity $95-97 \%$ at the temperature of $23{ }^{\circ} \mathrm{C}$. To ensure the steady state conditions of absorption were achieved, every measurement was performed 3 times in 30 minute intervals.

To characterize contactor performance, two major parameters of contactor devices (water absorption flux and water vapor stage cut) were extracted for each experimental conditions:

$$
J=\frac{Q_{\text {in }} \cdot \frac{P_{\text {sat }}\left(\mathrm{H}_{2} \mathrm{O}\right)}{P_{\text {in }}} \cdot R H_{\text {in }}-Q_{\text {out }} \cdot \frac{P_{\text {sat }}\left(\mathrm{H}_{2} \mathrm{O}\right)}{P_{\text {out }}} \cdot R H_{\text {out }}}{S},
$$

where $J$ - water absorption flux $\left[\mathrm{mol} / \mathrm{m}^{2}\right], Q_{i n}$ and $Q_{o u t}-$ inlet and outlet gas flux, respectively, $R H_{i n}$ and $R H_{\text {out }}$ - inlet and outlet relative humidity, $P_{\text {sat }}$ - saturated water vapor pressure at given temperature (calculation was performed via Antoinie Equation with coefficients determined by Stull [20] for temperature below $0{ }^{\circ} \mathrm{C}$ and 
TABLE 1. Characteristics of PP membrane contactor

\begin{tabular}{|c|c|}
\hline Parameter & \\
\hline Fiber outer diameter, mm & 0.31 \\
\hline Fiber inner diameter, mm & 0.24 \\
\hline Average pore size, $\mathrm{nm}$ & 200 \\
\hline Porosity, \% & 45 \\
\hline Module length, cm & 50 \\
\hline Number of fibers in module & 1200 \\
\hline Module contact area, $\mathrm{m}^{2}$ & 0.584 \\
\hline
\end{tabular}

coefficients determined by Bridgeman and Aldrich [21] for temperature above $\left.0{ }^{\circ} \mathrm{C}\right), P_{\text {in }}$ and $P_{\text {out }}-$ inlet and outlet air pressure and $S$ - membrane area:

$$
\eta=\frac{Q_{\text {in }} \cdot \frac{P_{\text {sat }}\left(\mathrm{H}_{2} \mathrm{O}\right)}{P_{\text {in }}} \cdot R H_{\text {in }}-Q_{\text {out }} \cdot \frac{P_{\text {sat }}\left(H_{2} O\right)}{P_{\text {out }}} \cdot R H_{\text {out }}}{Q_{\text {in }} \cdot \frac{P_{\text {sat }}\left(H_{2} O\right)}{P_{\text {in }}} \cdot R H_{\text {in }}},
$$

where $\eta$ - water vapor stage cut.

Membrane surface and porous structure were characterized by scanning electron microscopy (SEM) using Supra 50VP instrument.

\section{Results and discussion}

Micrographs of polypropylene hollow-fiber are represented on Fig. 2. Membrane porosity is represented by slit-like pores with sizes of $100 \times 500 \mathrm{~nm}$ (average pore size $\sim 200 \mathrm{~nm}$ ), typical for hot-stretched polymers. Such geometry of the pores can be considered optimal for providing maximal contact area while maintaining small pore sizes in the membrane. The last parameter is crucial to maximize critical pressure difference needed to overcome capillary forces for polymer wetting or bubbling at the gas-membrane-liquid interface. General characteristics of hollow fiber membrane and membrane contactor module are listed in the Table 1.
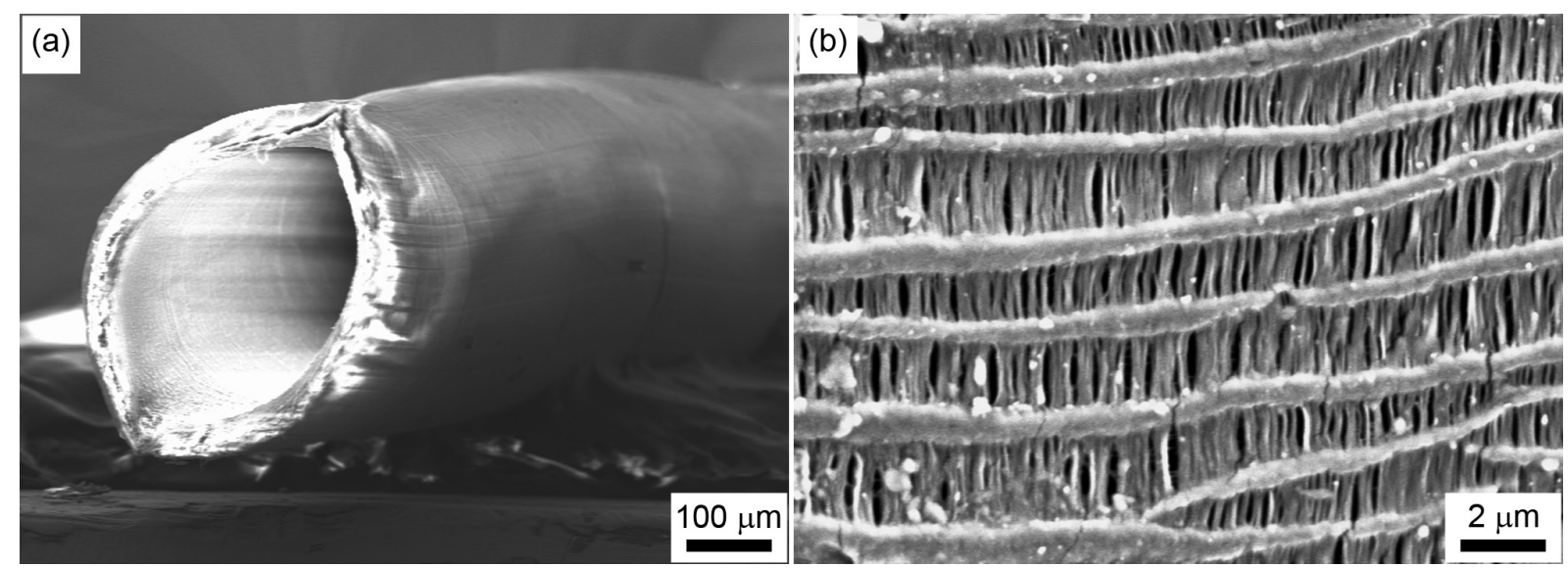

FIG. 2. Micrographs of individual hollow fiber cross-section (a) and enlarged view of membrane external surface (b)

The experiments $\mathrm{n}$ air dehumidification were started with revealing the role of humid air flow rate on the membrane contactor performance. Water vapor stage cut and vapor flux through the membrane show a strong dependence of residual water content on the air flow rate in the $300-3500 \mathrm{ml} / \mathrm{min}$ range (Fig. 3). Notably, the attained water dew point temperature in the retentate goes below $-28{ }^{\circ} \mathrm{C}$, illustrating efficiency of the lumen gas configuration as compared to earlier reports [19]. Increasing the gas flux leads to an increase in the water dew point and water vapor stage cut. To determine the limiting stage of absorption process, we have extracted the flux 
of water absorbed in the contactor (Fig. 3b) and compared the values with theoretical diffusion flux through the membrane. The diffusion flux of vapor was estimated using Knudsen diffusion mechanism [22] and the assumption that the membrane pores were filled with gas and absorption occurred at the external surface of fibers:

$$
J=-D_{K n u d s e n} \frac{P_{H_{2} O, a i r}-P_{H_{2} O, T E G}}{L \cdot R T},
$$

where $P_{\mathrm{H}_{2} \mathrm{O} \text {, air }}$ - partial pressure of water vapor in the inlet air, $P_{\mathrm{H}_{2} \mathrm{O}, T E G}$ - equilibrium pressure of water vapor at the triethylene glycol-air interface at a given water content in a liquid (for TEG concentration $99.8 \%$ the equilibrium partial pressure equals $0.0177 \mathrm{~mol} / \mathrm{m}^{3}$ ), $L$ - membrane thickness, $R$ - gas constant, $T$ - temperature, $D_{\text {Knudsen }}$ - Knudsen diffusion coefficient, determined as:

$$
D_{\text {Knudsen }}=\frac{\varepsilon d}{3 \tau} \sqrt{\frac{8 R T}{\pi M}},
$$

where $\varepsilon$ is the membrane porosity, $d$ - average pore diameter, $\tau$ - pore tortuosity, $M$ - water molecular weight. The estimated value of tortuosity in hot-stretched PP membranes was suggested to equal 2 [23]. The resulting Knudsen diffusion coefficient for average pore diameter of $200 \mathrm{~nm}$ and porosity of 0.45 is valued as $8.88 \cdot 10^{-6} \mathrm{~m}^{2} / \mathrm{s}$. Using the value with experimental partial pressure of water in humid air of $1.17 \mathrm{~mol} / \mathrm{m}^{3}$, equilibrium partial pressure over $99.8 \%$ TEG solution of $0.0177 \mathrm{~mol} / \mathrm{m}^{3}$, and membrane layer thickness of $35 \mathrm{~mm}$, one can estimate the water flux through the membrane in Knudsen regime as $0.293 \mathrm{~mol} /\left(\mathrm{m}^{2} \mathrm{~s}\right)$. The derived flux exceeds experimental value by three orders of magnitude, suggesting absorption reaction or absorbent feed to be the limiting step of the process.
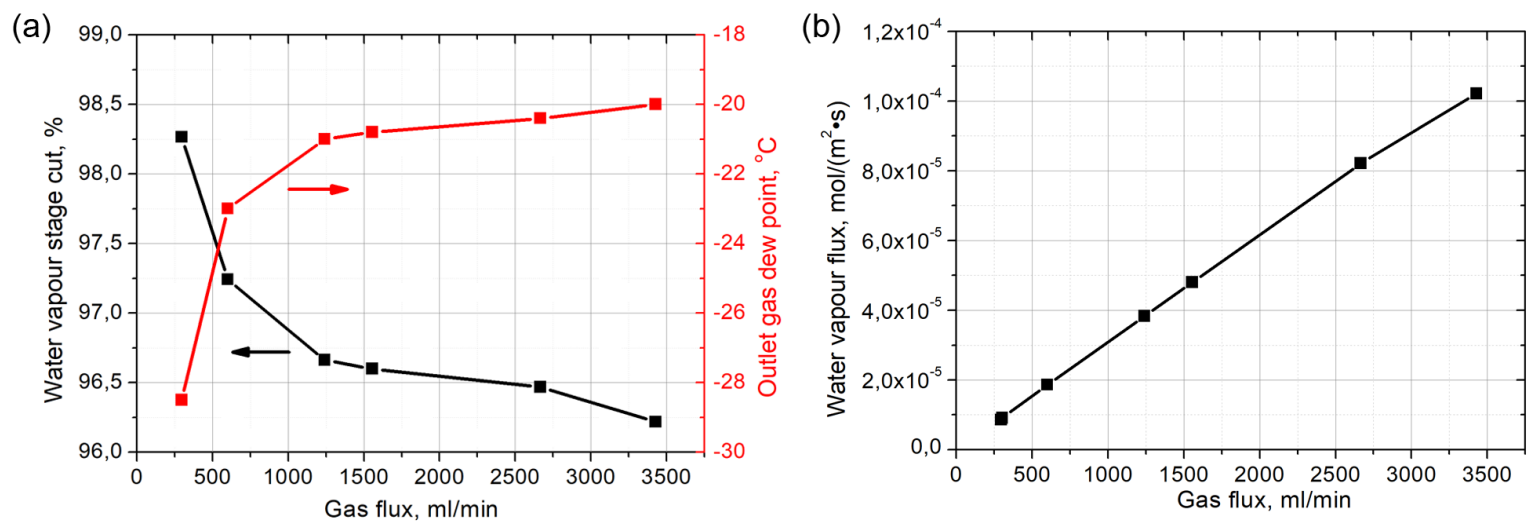

FIG. 3. Effect of gas flow rate on the water vapor stage cut, outlet gas dew point (a) and water vapor absorption flux (b). Inlet relative humidity $-96 \%$ at $23{ }^{\circ} \mathrm{C}$, TEG circulation rate $1000 \mathrm{ml} / \mathrm{min}$ and concentration $99.8 \%$

To check the effect of absorbent flux on the performance of membrane contactor, experiments with TEG circulation rate ranging from $166 \mathrm{ml} / \mathrm{min}$ to $1000 \mathrm{ml} / \mathrm{min}$ were carried out (Fig. 4). Moderate influence of TEG circulation rate on water vapor stage cut and dew point temperature of retentate flow was revealed. Increasing the circulation rate $\sim 7$ times leads to increase the absorption flux of only $5 \%$. This can be explained by a laminar flow of absorbent in the membrane contactor - for the given size of absorber (the inner diameter of $40 \mathrm{~mm}$ and the length of $400 \mathrm{~mm}$ ) liquid velocity is ranged from 0.002 to $0.012 \mathrm{~m} / \mathrm{s}$. These results suggest water diffusion into TEG volume to be a limiting stage of absorption process.

As the partial pressure of water vapor is strongly affected by $\mathrm{H}_{2} \mathrm{O}$ content in TEG, we have analyzed the role of this parameter on the contactor efficiency. Increasing water content in TEG solution leads to drastic decrease of water vapor stage cut and increase of dew point temperature of retentate due to growth of equilibrium water vapor pressure over the absorbent (Fig. 5). Nevertheless even at $3 \%$ water content in TEG, the dew point of the retentate is reduced to relatively low value of $4{ }^{\circ} \mathrm{C}$ with vapor stage cut over $50 \%$. Thus water pressure over contacting liquid is seemed to be key parameter for the contactor performance. Notably, the outlet gas dew points were found relatively close to equilibrium values, especially in case of high vapor humidity [9]. This illustrates an efficiency of the proposed method for gas dehumidification. Using a lean TEG solution and a high circulation, the rate dew point of feed gas can be decreased down to $-30{ }^{\circ} \mathrm{C}$ for the contactor performance of $30-60 \mathrm{l} /\left(\mathrm{m}^{2} \mathrm{~h}\right)$. This result demonstrates that membrane contactors with shell side flow of TEG can be utilized for air and natural gas dehumidification. 

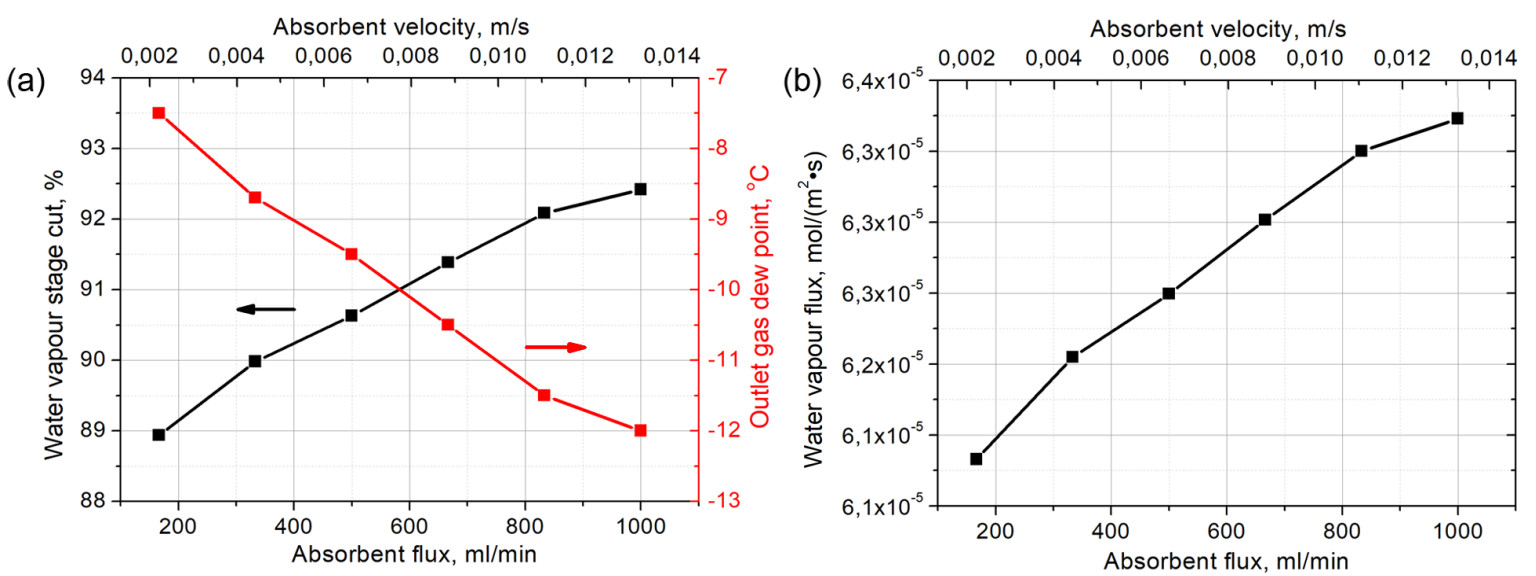

FIG. 4. Effect of absorbent flow rate on the water vapor stage cut, outlet gas dew point (a) and water vapor absorption flux (b). Inlet relative humidity $-96 \%$ at $23{ }^{\circ} \mathrm{C}$, gas flux $-2200 \mathrm{ml} / \mathrm{min}$, TEG concentration $99.5 \%$

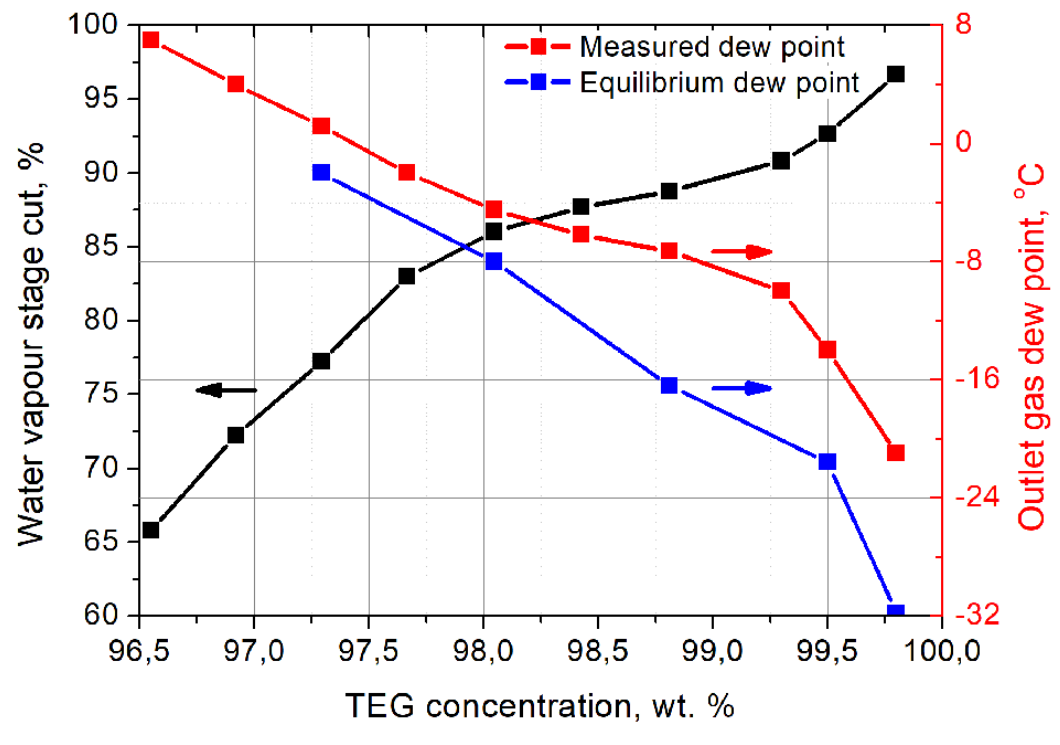

FIG. 5. Effect of TEG concentration on the water vapor stage cut, outlet gas dew point and equilibrium dew point for TEG with given concentration. Inlet relative humidity - $96 \%$ at $23{ }^{\circ} \mathrm{C}$, gas flux $-2200 \mathrm{ml} / \mathrm{min}$, TEG circulation rate $-1000 \mathrm{ml} / \mathrm{min}$

\section{Conclusions}

Thus, porous hollow-fiber membrane used in gas-liquid membrane contactors with lumen gas flow configuration can be successfully utilized for air dehumidification using the triethylene glycol as a desiccant. Examination of feed gas flow, absorbent circulation rate and TEG water content effects on water vapor transport through membrane reveal partial water pressure over absorbent at gas-liquid interface to be the key parameter for the contactor performance, while diffusion of dissolved water into glycol volume appears as a limiting stage of absorption process. Utilization of dry TEG solution at high absorbent circulation rates allows one to decrease the dew point of the feed gas down to $\sim-30{ }^{\circ} \mathrm{C}$ from $96 \%$ humidity level at standard conditions. These results reveal the potential of using porous membrane contactors with lumen gas flow configuration for air dehumidification and natural gas conditioning for pipeline transport. 


\section{Acknowledgements}

The work is supported by the Ministry of education and science of the Russian Federation within a Federal Targeted Programme for "Research and Development in Priority Areas of Development of the Russian Scientific and Technological Complex for 2014 - 2020” (Agreement No. 14.604.21.0177, unique Project Identification RFMEFI60417X0177).

\section{References}

[1] Owen M.S. Handbook: Fundamentals, American Society of Heating, Refrigerating, and Air-Conditioning Engineers. ASHRAE, Atlanta, $2005,544 \mathrm{p}$.

[2] Pyatkov E.S., Surtaev V.N., et al. Conditioning of associated petroleum gas using capillary condensation technique with asymmetric microporous anodic alumina membranes. Oil Industry, 2016, 5, P. 82-85.

[3] Petukhov D.I., Berekchiian M.V., et al. Experimental and Theoretical Study of Enhanced Vapor Transport through Nanochannels of Anodic Alumina Membranes in a Capillary Condensation Regime. Journal of Physical Chemistry C, 2016, 120 (20), P. 10982-10990.

[4] Öberg V., Goswami D.Y. Experimental Study of the Heat and Mass Transfer in a Packed Bed Liquid Desiccant Air Dehumidifier. Journal of Solar Energy Engineering, 1998, 120, P. 289-297.

[5] Wang W., Wu L., et al. An Overview of Adsorbents in the Rotary Desiccant Dehumidifier for Air Dehumidification. Drying Technology, 2013, 31, P. 1334-1345.

[6] Lin H., Thompson S.M., et al. Dehydration of natural gas using membranes. Part I: Composite membranes. Journal of Membrane Science, 2012, 413-414, P. 70-81.

[7] Rafique M.M., Gandhidasan P., Bahaidarah H.M.S. Liquid desiccant materials and dehumidifiers - A review. Renewable \& Sustainable Energy Reviews, 2016, 56, P. 179-195.

[8] Liu X.-H., Yi X.-Q., Jiang Y. Mass transfer performance comparison of two commonly used liquid desiccants: LiBr and LiCl aqueous solutions. Energy Conversion and Management, 2011, 52, P. 180-190.

[9] Kohl A.L., Nielsen R. Richard B. Gas purification, Gulf Pub, Oxford, 1997, 900 p.

[10] Petukhov D.I., Poyarkov A.A., et al. Removal of acidic components of associated petroleum gas by pertraction on microporous membranes. Oil Industry, 2016, 11, P. 55-58.

[11] Ovcharova A.A., Vasilevsky V.P., et al. Porous hollow fiber membranes with varying hydrophobic-hydrophilic surface properties for gas-liquid membrane contactors. Petroleum Chemistry, 2016, 56 (11), P. 1066-1073.

[12] Ovcharova A., Vasilevsky V., et al. Polysulfone porous hollow fiber membranes for ethylene-ethane separation in gas-liquid membrane contactor. Separation and Purification Technology, 2017, 183, P. 162-172.

[13] Nieves-Remacha M.J., Kulkarni A.A., Jensen K.F. Gas-Liquid Flow and Mass Transfer in an Advanced-Flow Reactor. Industrial \& Engineering Chemistry Research, 2013, 52, P. 8996-9010.

[14] Isetti C., Nannei Enrico M.A. On the application of a membrane air - liquid contactor for air dehumidification. Energy and Buildings, 1997, 25, P. 185-193.

[15] Huang S.-M., Zhang L.-Z. Researches and trends in membrane-based liquid desiccant air dehumidification. Renewable \& Sustainable Energy Reviews, 2013, 28, P. 425-440.

[16] Huang S.-M., Zhang L.-Z., Tang K., Pei L.-X. Fluid flow and heat mass transfer in membrane parallel-plates channels used for liquid desiccant air dehumidification. International Journal of Heat and Mass Transfer, 2012, 55, P. 2571-2580.

[17] Huang S.-M., Zhang L.-Z., Pei L.-X. Transport Phenomena in a Cross-Flow Hollow Fibre Membrane Bundle Used for Liquid Desiccant Air Dehumidification. Indoor and Built Environment, 2013, 22, P. 559-574.

[18] Usachov V.V, Teplyakov V.V, Okunev A.Y., Laguntsov N.I. Membrane contactor air conditioning system: Experience and prospects. Separation and Purification Technology, 2007, 57, P. 502-506.

[19] Fakharnezhad A., Keshavarz P. Experimental investigation of gas dehumidification by tri-ethylene glycol in hollow fiber membrane contactors. Journal of Industrial and Engineering Chemistry, 2016, 34, P. 390-396.

[20] Stull D.R. Vapor Pressure of Pure Substances. Organic and Inorganic Compounds. Industrial \& Engineering Chemistry, 1947, 39, P. 517540.

[21] Bridgeman O.C., Aldrich E.W. Vapor Pressure Tables for Water. Journal of Heat Transfer, 1964, 86, P. $279-286$.

[22] Petukhov D.I., Eliseev A.A. Gas permeation through nanoporous membranes in the transitional flow region. Nanotechnology, 2016, 27, 085707.

[23] Yan S.-P., Fang M.-X., et al. Experimental study on the separation of $\mathrm{CO}_{2}$ from flue gas using hollow fiber membrane contactors without wetting. Fuel Processing Technology, 2007, 88, P. 501-511. 